\title{
Effect of 2-propanol Immersing on Organohalide Perovskite Layer in Perovskite Solar Cells Fabricated by Two-step Method
}

\author{
Daiki Okawa, Yoshiyuki Seike, and Tatsuo Mori * \\ Department of Electrical and Electronics Engineering, Graduate School of Engineering, \\ Aichi Institute of Technology, \\ 1247 Yachigusa, Yakusa-cho, Toyota, Aichi 470-0392, Japan \\ *t2mori@aitech.ac.jp
}

\begin{abstract}
In the 2-step method of $\mathrm{CH}_{3} \mathrm{NH}_{3} \mathrm{PbI}_{3}$, the $\mathrm{CH}_{3} \mathrm{NH}_{3} \mathrm{PbI}_{3}$ layer is converted using methylammonium iodide (MAI) after coating a $\mathrm{PbI}_{2}$ layer. Although the use of dimethyl sulfoxide (DMSO) is reported to enhance the crystal quality of perovskite layer, we could not achieve the similar result. We studied the relationship between the layer properties of $\mathrm{PbI}_{2}$ and the DMSO content in solvent. In addition, we checked the layer properties of perovskite layer and the photovoltaic performance of the cells with the above perovskite active layers. We found the immerse process of $\mathrm{PbI}_{2}$ in 2-propanol influences the reconstruction of $\mathrm{PbI}_{2}$ morphology and the diffusion process of MAI depends on the $\mathrm{PbI}_{2}$ morphology.

Keywords: Organic perovskite, Solar cell, 2-step method, Immersion treatment, XRD, IR spectroscopy
\end{abstract}

\section{Introduction}

12 years passed over since Miyasaka group used a perovskite material as an absorbance dye of dyesensitized solar cell in 2009[1]. The power conversion efficiency (PCE) of a whole solid perovskite solar cell approached to $11 \%[2]$. The PCE of perovskite solar cell is reported to be beyond $25 \%$ in 2020[3]. This PCE is almost comparable to that of mono-crystal silicon solar cell. The fabrication methods of perovskite solar cells are categorized by a dry process, vacuum-deposition $[4,5]$ and a wet process. The stable and high quality perovskite layer can be fabricated by the vacuumdeposition. However, the use of vacuum equipment have a disadvantage for a low-cost manufacture and massive production. Therefore, the production of perovskite solar cells will carry out by a wet process. In a wet (solution) fabrication process of perovskite layer, two main methods are well-known: 1-step method [6,7] and 2-step method[8]. In 1-step method, the solution including all materials is applied in one coating. On the other hand, in 2-step method, the post material (i.e. methylammonium iodide (MAI)) is applied in second coating after applying one material (i.e. $\mathrm{PbI}_{2}$ ) in first coating. Finally the precursor layer is converted to perovskite (i.e. $\mathrm{CH}_{3} \mathrm{NH}_{3} \mathrm{PbI}_{3}$ ).

The formation process of crystal is classified by the formation of crystal nuclei and the growth of crystal. In the 1-step method, both processes are thought to occur at a time in the converted process. When the formation of crystal nuclei and the growth of crystal progress at a time, it is possible to form small crystals because each crystal growth is blocked each other. Therefore, some post treatments are often used in the 1-step method. One is the solvent engineering (another name, anti-solvent) method[9] and the other is the solvent annealing method[10]. On the other hand, if the formation of crystal is optimally controlled in the 2-step method, the formation of crystal nuclei will occur at the surface of the pre-coated layer and the crystal will grow gradually to the direction of thickness. Therefore, a high quality perovskite layer can be fabricated by the ideal 2-step method. It is important to study the formation process of perovskite layer in detail. We reported the fabrication processes of perovskite layer in the previous papers, i.e., air 
flow[11,12], solvent anneal[13,14], and electron extraction layer[15-17].

$\mathrm{Wu}$ et.al. reported that the $\mathrm{PbI}_{2}$ layer fabricated from dimethyl sulfoxide (DMSO) solution is amorphous[18]. Other paper also reported the similar result[19-21]. The high-quality perovskite layer without a resultant $\mathrm{PbI}_{2}$ layer can be converted from the amorphous $\mathrm{PbI}_{2}$ layer. Although we attempted the perovskite layer using DMSO solvent in the 2-step method, unfortunately our perovskite layers were not always converted perfectly. In this paper, we report the effect of DMSO solvent to the fabrication of $\mathrm{PbI}_{2}$ and perovskite layers.

\section{Experimental}

2.1. Materials and fabrication

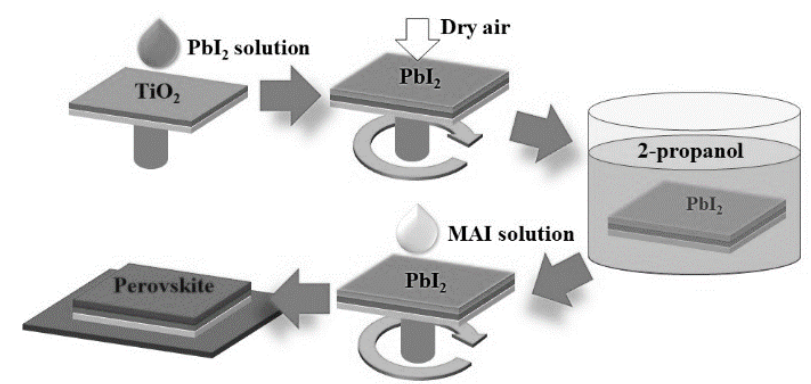

Fig. 1. Schematic of the 2-step method for the fabrication of $\mathrm{CH}_{3} \mathrm{NH}_{3} \mathrm{PbI}_{3}$ layer.

Fluorine-doped tin oxide (FTO) substrates were cleaned by water, organic solvents and tetramethylammonium hydroxide. $30 \mathrm{~nm}$-thick $\mathrm{TiO}_{2}$ compact layer was fabricated as an electron extraction layer on FTO electrodes. $\mathrm{PbI}_{2}$ layers were spin-coated from the mixture solution of DMSO and DMF. The $\mathrm{PbI}_{2}$ of $461 \mathrm{mg}$ was dissolved in the mixture solvent of $1 \mathrm{~mL}$. The composition of the mixture solvents were DMSO 0, 25, 50, 75, and 100 vol\%. The spin-coated $\mathrm{PbI}_{2}$ layers were immersed in 2-propanol for 5 minutes to obtain a shiny black surface under air atmosphere. The spin-coat condition was $4,000 \mathrm{rpm}, 30 \mathrm{~s}$ with the air-flow procedure. Detailed air-flow experimental procedure is described in the previous paper[11-13]. The $\mathrm{PbI}_{2}$ layers were converted to perovskite layer by dipping in MAI solution for 30 seconds. MAI $30 \mathrm{mg}$ was dissolved in 2-propanol of $3 \mathrm{~mL}$. The perovskite $\left(\mathrm{CH}_{3} \mathrm{NH}_{3} \mathrm{PbI}_{3}\right)$ layers were annealed at $100{ }^{\circ} \mathrm{C}, 10$ minutes on a hotplate.

In the fabrication of PV cells, $100 \mathrm{~nm}$-thick spiroMeOTAD layer was fabricated on perovskite layer as a hole extraction layer. $50 \mathrm{~nm}$-thick Au was vacuum-deposited as a top electrode. The structure of our devices were $\mathrm{FTO} / \mathrm{TiO}_{2} / \mathrm{CH}_{3} \mathrm{NH}_{3} \mathrm{PbI}_{3}$ /spiro$\mathrm{MeOTAD} / \mathrm{Au}$.

\subsection{Measurements}

Specimen thickness were measured with a thickness tester (Kosaka Laboratory, Surfcorder, ET200). X-ray diffraction (XRD) patterns were recorded in the $2 \theta$ range of $5-60^{\circ}$ using an X-ray diffractometer (Rigaku RINT2500/PC) with $\mathrm{Cu} \mathrm{Ka}$ radiation $(40 \mathrm{kV}, 100 \mathrm{~mA})$. The infrared spectroscopic spectra were measured using the IR Prestige 21 (Shimadzu). Current-voltage (J-V) characteristics were measured using a digital source meter (Agilent B2901A). A 150 W xenon lamp (Bunkoukeiki, Otento-SUN3 Xe-150) was used as the solar simulator of the AM $1.5 \mathrm{G}$ condition (100 $\mathrm{mW} / \mathrm{cm}^{2}$ )

\section{Results and discussion}

Fig. 2 shows the thickness of $\mathrm{PbI}_{2}$ immersed in 2propernol and the $\mathrm{CH}_{3} \mathrm{NH}_{3} \mathrm{PbI}_{3}$ layers converted from the $\mathrm{PbI}_{2}$ layers. The thickness of $\mathrm{PbI}_{2}$ layers decreases with increasing DMSO content. Since the unit cell of $\mathrm{CH}_{3} \mathrm{NH}_{3} \mathrm{PbI}_{3}$ is larger than the unit cell of $\mathrm{PbI}_{2}$, the thickness of $\mathrm{CH}_{3} \mathrm{NH}_{3} \mathrm{PbI}_{3}$ layer is thicker than the thickness of original $\mathrm{PbI}_{2}$ layer. Of course, the thickness of converted $\mathrm{CH}_{3} \mathrm{NH}_{3} \mathrm{PbI}_{3}$ layer depends on that of original $\mathrm{PbI}_{2}$ layer.

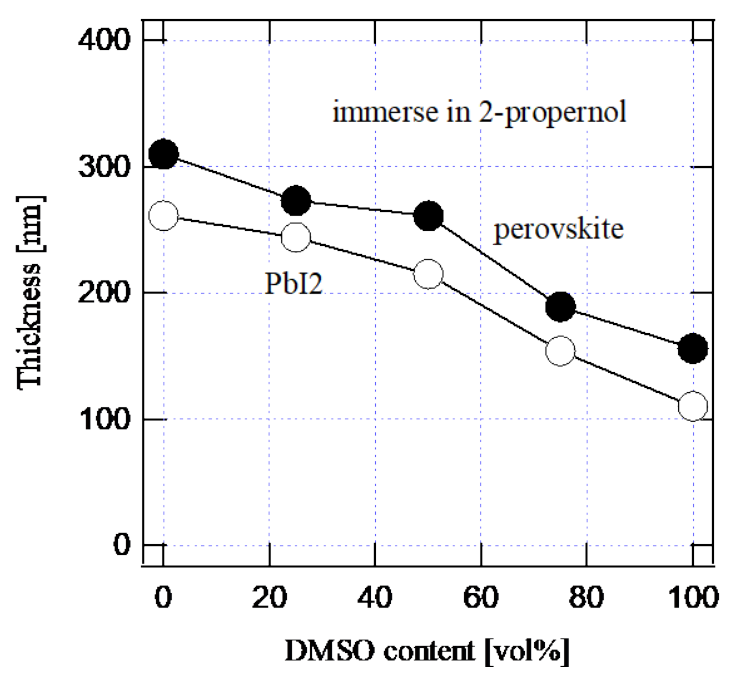

Fig. 2. The thickness of $\mathrm{PbI}_{2}$ layers immersed in 2propernol and converted $\mathrm{CH}_{3} \mathrm{NH}_{3} \mathrm{PbI}_{3}$ layers.

Figs. 3 (a) and 3(b) show the XRD patterns of $\mathrm{PbI}_{2}$ and perovskite layers depending on DMSO content in solvent. The peaks of $2 \theta=12.6^{\circ}$ and $13.8^{\circ}$ are due to the peak of $\mathrm{PbI}_{2}(001)$ and $\mathrm{CH}_{3} \mathrm{NH}_{3} \mathrm{PbI}_{3}(110)$, respectively. The peaks of $\mathrm{PbI}_{2}(001)$ and perovskite(110) are observed in XRD patterns in Fig. 3 (b). In most perovskite specimens, the resultant $\mathrm{PbI}_{2}$ layer exists. The addition of DMSO does not diminish the crystallinity of $\mathrm{PbI}_{2}$ but enhances the crystallinity. For example, the thickness of $\mathrm{PbI}_{2}$ layer 
fabricated from DMSO 50 vol\%-solvent is twice or more thicker than that of $\mathrm{PbI}_{2}$ layer fabricated from DMSO 100vol\%-solvent, but the peak intensity of $\mathrm{PbI}_{2}(001)$ of the former is a half or less lower than that of the latter. The $\mathrm{PbI}_{2}$ layer fabricated from only DMF solvent is low-crystalline. This result is inconsistent with the previous reports[19-21]. The boiling point of $\mathrm{DMF}, 153^{\circ} \mathrm{C}$ is lower than that of $\mathrm{DMSO}, 189^{\circ} \mathrm{C}$. When the drying rate is fast, the crystallinity is poorer because of the inhibition of crystal growth. Therefore, if $\mathrm{PbI}_{2}-\mathrm{DMSO}$ complex are not formed, we speculate the crystallinity of $\mathrm{PbI}_{2}$ layers fabricated by DMSO solution ought to be higher than that of $\mathrm{PbI}_{2}$ layers fabricated by DMF solution. The crystallinity of $\mathrm{PbI}_{2}$ layers fabricated by DMF solution strongly depends on the fabrication atmosphere (temperature, DMF gas concentration, etc.).
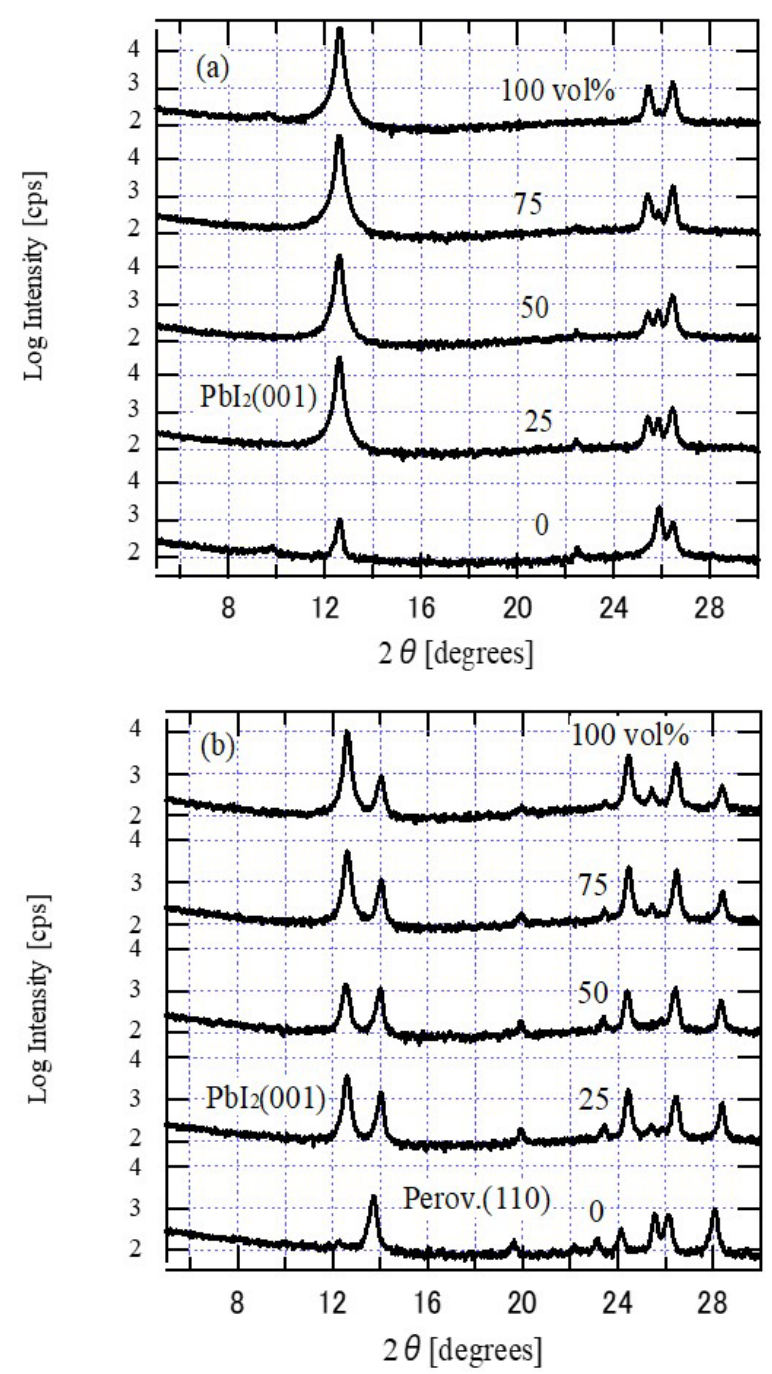

Fig. 3. The XRD pattern of $\mathrm{PbI}_{2}$ layers fabricated using the solvents with DMSO content of $0,25,50,75$, and 100 vol\% (a) and perovskite layers converted from the above $\mathrm{PbI}_{2}$ (b).
Fig. 4 shows the absorption spectra of perovskite layers which are converted from $\mathrm{PbI}_{2}$ layers fabricated using the solvents with different DMSO contents. As DMSO content increases, the absorbance of the perovskite layer decreases because of the decrease in thickness. The absorbance of perovskite layer is proportional to the thickness.

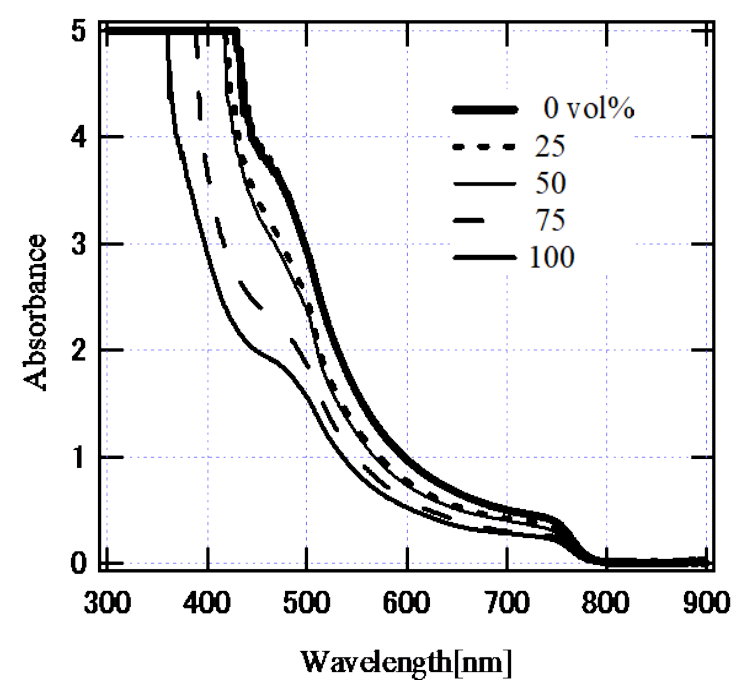

Fig. 4. Absorption spectra of perovskite layers converted using $\mathrm{PbI}_{2}$ layers fabricated with different DMSO contents in solvent.

Fig. 5 shows the photocurrent curves of the perovskite solar cells fabricated using $\mathrm{PbI}_{2}$ layers converted with different DMSO contents in solvent. Table 1 shows the PV parameters of perovskite solar cells in Fig. 5. As DMSO content increases, the short-circuit current density $\left(\mathrm{J}_{\mathrm{SC}}\right)$, open circuit voltage $\left(\mathrm{V}_{\mathrm{OC}}\right)$, and fill factor (FF) decrease. Consequently the PCE of the DMSO 0vol\%specimen is the maximum. The slight decrease of $\mathrm{J}_{\mathrm{SC}}$ is caused by the decrease in optical absorption, i.e. the decrease in the thickness of perovskite layer. However, the ratios of thickness and of absorption (@,700 nm) for 0 vol\% per 100 vol\% perovskite layer are 0.50 and 0.57 , respectively. The ratio of $\mathrm{PbI}_{2}(001)$ peak in XRD for $0 \mathrm{vol} \%$ per $100 \mathrm{vol} \%$ perovskite layer is 0.44 . The difference of $\mathrm{J}_{\mathrm{SC}}$ between 0 vol $\%$ and $100 \mathrm{vol} \%$ specimens cannot be quantitatively explained by the amount of light absorption. In spite of small light absorption, the fact that the $100 \mathrm{vol} \%$ specimen shows the comparable $\mathrm{J}_{\mathrm{SC}}$ to the $0 \mathrm{vol} \%$ specimen may suggest the formation of high-quality perovskite layer. On the other hand, the decreases in $\mathrm{V}_{\mathrm{OC}}$ and FF suggest a poor device performance. 


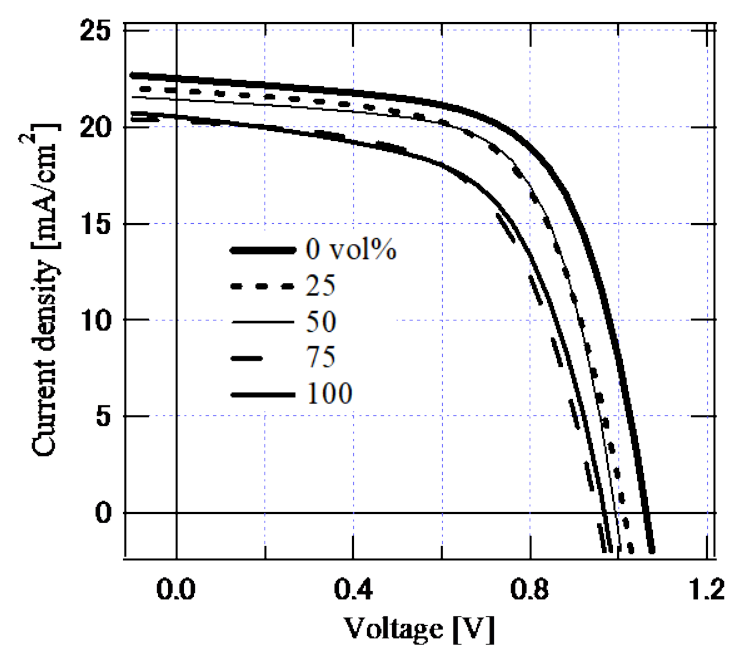

Fig. 5. Photocurrent curves of the perovskite solar cells fabricated using $\mathrm{PbI}_{2}$ layers converted with different DMSO contents in solvent.

Table 1. Summary of PV parameters of cells in Fig. 5.

\begin{tabular}{|c|c|c|c|c|c|}
\hline $\mathrm{DMSO}[\mathrm{vol} \%]$ & 0 & 25 & 50 & 75 & 100 \\
\hline $\mathrm{J}_{\mathrm{SC}}\left[\mathrm{mA} / \mathrm{cm}^{2}\right]$ & 22.4 & 21.8 & 21.4 & 20.3 & 20.5 \\
\hline $\mathrm{V}_{\mathrm{OC}}[\mathrm{V}]$ & 1.05 & 1.00 & 0.976 & 0.930 & 0.949 \\
\hline $\mathrm{FF}$ & 0.585 & 0.583 & 0.614 & 0.552 & 0.551 \\
\hline $\mathrm{PCE}[\%]$ & 13.8 & 12.7 & 12.8 & 10.5 & 10.7 \\
\hline
\end{tabular}

We measured some EQE spectra of 0 vol\%(DMF) and $100 \mathrm{vol} \%$ (DMSO) specimens. However, the Jsc calculated from IPCE spectra are 24.7 and 18.2 $\mathrm{mA} / \mathrm{cm}^{2}$, respectively. Since the former thickness of perovskite layer is twice thicker than the latter thickness, the crystalline quality of perovskite layer in the $100 \mathrm{vol} \%(\mathrm{DMSO})$ specimen may be higher than that of perovskite layer in the $0 \mathrm{vol} \%(\mathrm{DMF})$ specimen.

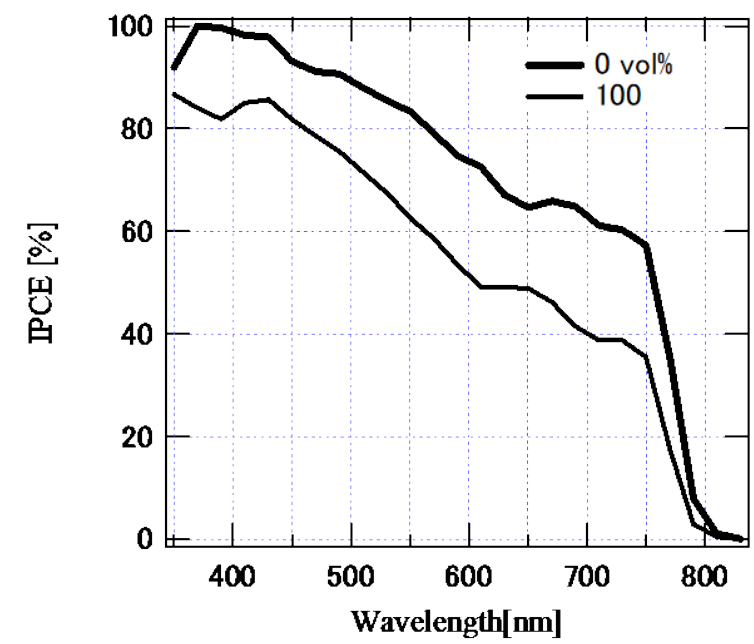

Fig. 6. IPCE spectra of the perovskite solar cells fabricated using $\mathrm{PbI}_{2}$ layers with 0 vol\%(DMF) and 100 vol\%(DMSO).
The $\mathrm{PbI}_{2}$ layer fabricated using only DMF is lowcrystalline in our result. The device performance of the $0 \mathrm{vol} \%$ specimen is the best of five specimens. As reported in the previous papers[18-21], when the perovskite layer converted from the low ${ }^{-}$ crystalline $\mathrm{PbI}_{2}$ is used, the device performance is improved.

We compared our fabrication process with the previous fabrication processes. In our process, the immersion treatment in 2-propanol is carried out after spin-coating $\mathrm{PbI}_{2}$ layers. Therefore, the effect of immersion treatment on the $\mathrm{PbI}_{2}$ layer was estimated by IR spectroscopy.
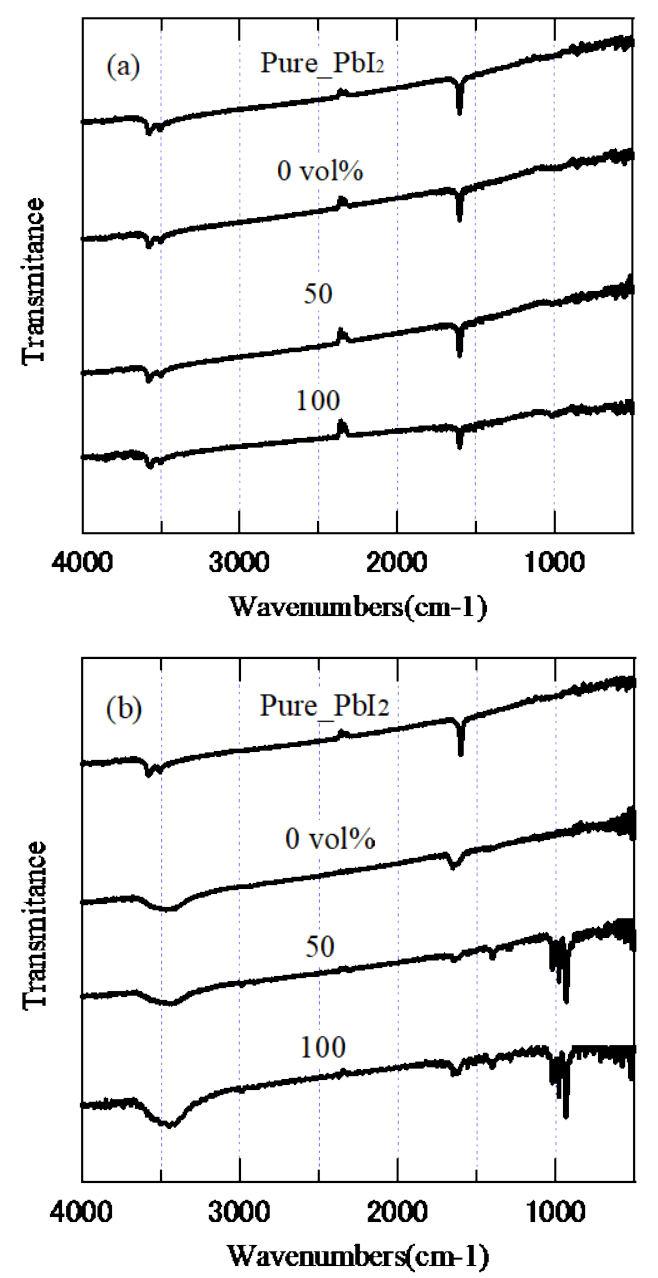

(c)

(d)

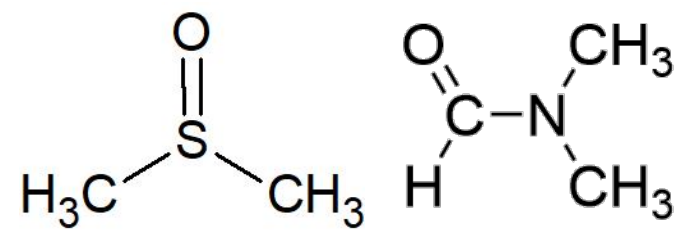

Fig. 7. The IR spectra of the fine $\mathrm{PbI}_{2}$ layers fabricated (a) with and (b) without the immersion treatment in 2propanol: the chemical structures of DMSO (c) and DMF (d); DMSO contents of 0, 50, $100 \mathrm{vol} \%$. 
Figs. 7 (a) and (b) show the IR spectra of the fine $\mathrm{PbI}_{2}$ layer fabricated with and without the immersion treatment in 2-propanol. The absorption of $1,000 \mathrm{~cm}^{-1}$ is due to the stretching vibration of $\mathrm{S}$ $=\mathrm{O}$. The absorption of the stretching vibration of $\mathrm{C}$ - $\mathrm{N}$ is around $1,200 \mathrm{~cm}^{-1}$.

The IR spectra of all immersed $\mathrm{PbI}_{2}$ pellets are same and either absorption is not observed in Fig. 7 (a). It is thought that any resultant solvent is little included in the immersed $\mathrm{PbI}_{2}$ layers. On the other hand, the absorption of $\mathrm{SO}$ is observed in the IR spectra of non-immersed $\mathrm{PbI}_{2}$ pellets of 50 and 100 vol\% in Fig. 7 (b). However, the absorption of $\mathrm{CN}$ is not observed in the IR spectra of non-immersed $\mathrm{PbI}_{2}$ pellet of $0 \mathrm{vol} \%$.

This result suggests that the DMSO molecules remain in the $\mathrm{PbI}_{2}$ layers fabricated from DMSO solvents but the DMSO molecules are removed by the immersion treatment in 2-propanol.

Fig. 8 shows the IR spectra of $\mathrm{PbI}_{2}$ layers fabricated with different immersion times. When the immersing time is $0 \mathrm{~min}$ (non-immersion), the absorption of DMSO is observed at $1,000 \mathrm{~cm}^{-1}$. However, the absorption of $\mathrm{S}=\mathrm{O}$ disappears after 5 min immersion. Residual DMSO molecules in the $\mathrm{PbI}_{2}$ layer are removed by 2-propanol immersion for 5 minutes. In addition, $\mathrm{PbI}_{2}$ crystals are reconstructed when the DMSO molecules are removed. Consequently, the crystallinity of $\mathrm{PbI}_{2}$ will be improved by 2-propanol immersion treatment.

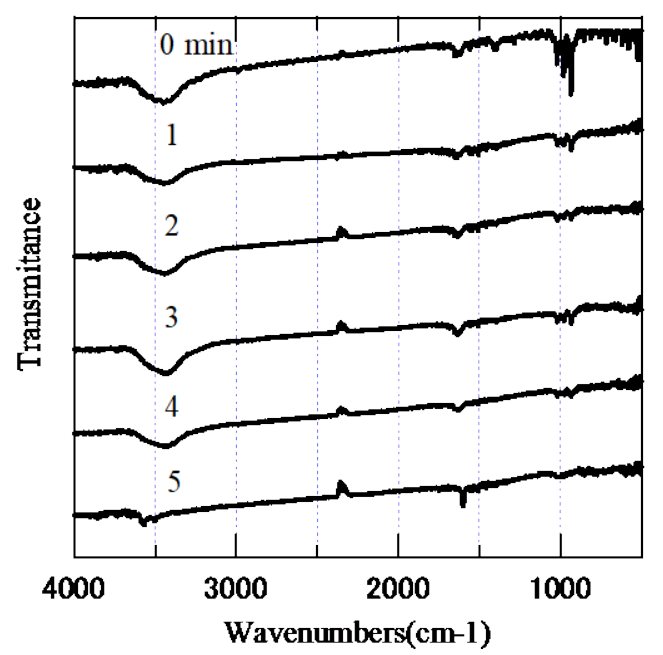

Fig. 8. The IR spectra of the $\mathrm{PbI}_{2}$ layer fabricated from 100 vol\% DMSO solvent by changing an immersion time.

Figs. 9 (a) and (b) show the XRD patterns of nonimmersed $\mathrm{PbI}_{2}$ layers fabricated from different DMSO solvents and the perovskite layers converted the above $\mathrm{PbI}_{2}$ layers. The peaks of $2 \theta=9.7^{\circ}, 12.6^{\circ}$ and $13.8^{\circ}$ are due to the peak of $\mathrm{PbI}_{2}(\mathrm{DMSO}) \mathrm{x}$,
$\mathrm{PbI}_{2}(001)$ and $\mathrm{CH}_{3} \mathrm{NH}_{3} \mathrm{PbI}_{3}(110)$, respectively. The peaks of $\mathrm{PbI}_{2}(001)$ and perovskite(110) are observed in XRD patterns in Fig. 9 (b). When DMSO is included in the solvent for $\mathrm{PbI}_{2}, \mathrm{DMSO}$ molecules form the complex with $\mathrm{PbI}_{2}$ as reported in the previous paper[19]. Since these complexes inhibit the smooth crystal growth of $\mathrm{PbI}_{2}$. Consequently, $\mathrm{PbI}_{2}$ layers fabricated from DMSO solvents are low-crystalline.
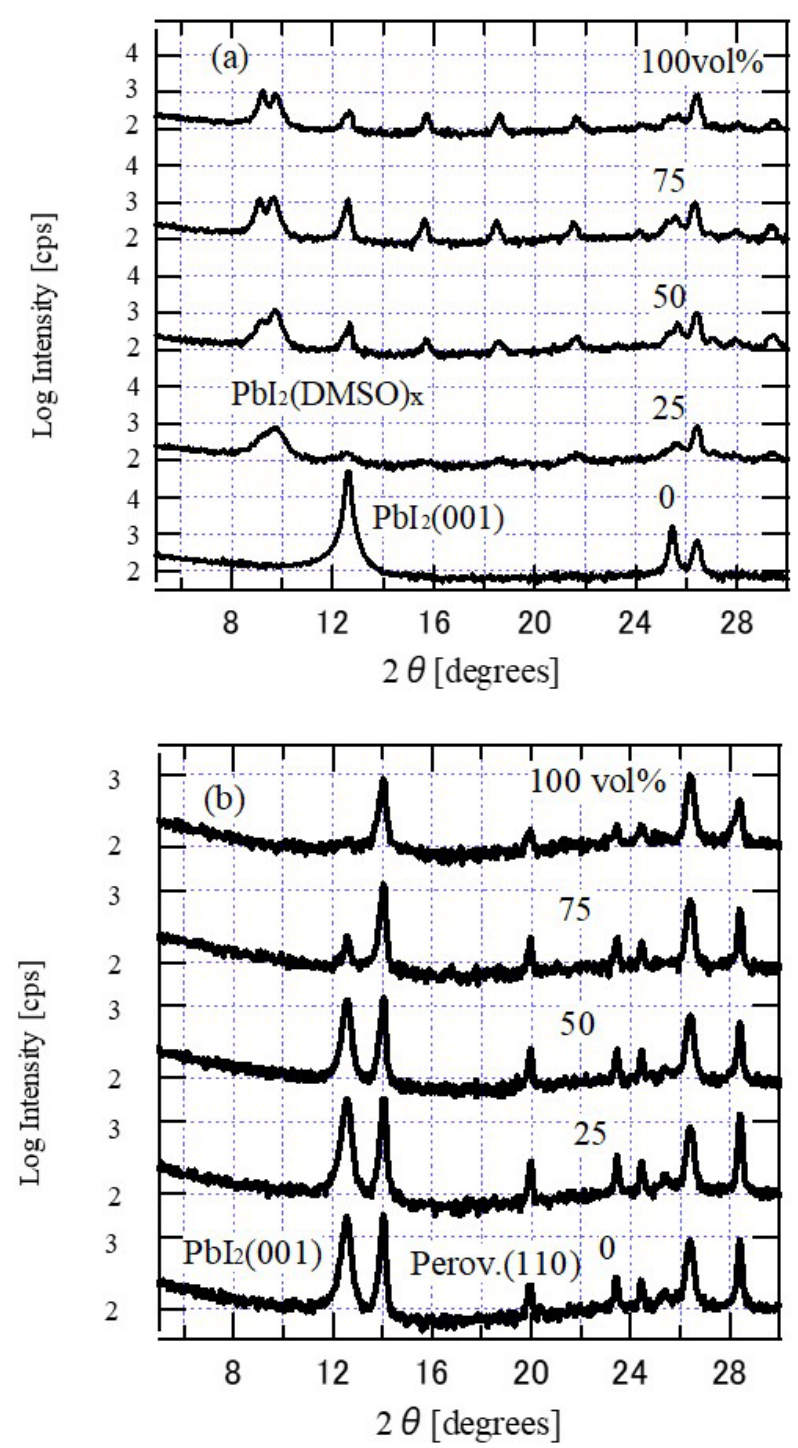

Fig. 9. The XRD patterns of (a) non-immersed $\mathrm{PbI}_{2}$ layers fabricated and (b) perovskite layers fabricated using the above $\mathrm{PbI}_{2}$ layers.

$\mathrm{PbI}_{2}$ are converted from the surface contacted with MAI. When the diffusion rate of $\mathrm{MAI}$ in $\mathrm{PbI}_{2}$ layer is slower than the conversion rate of $\mathrm{CH}_{3} \mathrm{NH}_{3} \mathrm{PbI}_{3}$, the supply of MAI from the contacted surface will be suppressed by the compact $\mathrm{CH}_{3} \mathrm{NH}_{3} \mathrm{PbI}_{3}$ thin layer because the unit cell of $\mathrm{CH}_{3} \mathrm{NH}_{3} \mathrm{PbI}_{3}$ is larger than the unit cell of $\mathrm{PbI}_{2}$. MAI will be not supplied in the $\mathrm{PbI}_{2}$ region separated from the surface. 
Consequently, the resultant $\mathrm{PbI}_{2}$ layer occur in $\mathrm{CH}_{3} \mathrm{NH}_{3} \mathrm{PbI}_{3}$ layer. When the low-crystalline $\mathrm{PbI}_{2}$ layer is formed, MAI can be rapidly supplied to the deep $\mathrm{PbI}_{2}$ region through free volumes. Therefore, it is thought that there are little the resultant $\mathrm{PbI}_{2}$ layers in the low-crystalline $\mathrm{PbI}_{2}$ layer. How we check the device performance.

\section{Conclusion}

We fabricated $\mathrm{PbI}_{2}$ layers fabricated from different DMSO contents in solvent and the $\mathrm{CH}_{3} \mathrm{NH}_{3} \mathrm{PbI}_{3}$ layer converted from the above $\mathrm{PbI}_{2}$ layers. First we did not obtain the similar results in the previous papers but found to be caused by the immersion treatment in 2-propanol. Although the addition of DMSO in solvent produced the complex $\mathrm{PbI}_{2}$ (DMSO)x, DMSO molecules were removed by the immersion of $\mathrm{PbI}_{2}$ in 2-propanol for $5 \mathrm{~min}$. The addition of DMSO enhanced low-crystalline. The low-crystalline $\mathrm{PbI}_{2}$ layer is effective for the rapid conversion to $\mathrm{CH}_{3} \mathrm{NH}_{3} \mathrm{PbI}_{3}$ layer without a resultant $\mathrm{PbI}_{2}$ layer.

\section{Acknowledgements}

This research is partially obtained by the AIT Special Grant "Development of Hybrid-Power Science \& Technology for Green-Energy", and the AIT special grant for Education and Research.

\section{References}

1. A. Kojima, K. Teshima, Y. Shirai, and T. Miyasaka, J. Am. Chem. Soc., 131 (2009) 6050.

2. M. M. Lee, J. Teuscher, T. Miyasaka, T. N. Murakami, and H. J. Snaith, Science, 338 (2012) 643.

3. NREL, URL https://www.nrel.gov/pv/ deviceperformance.html.

4. M. Liu, M. B. Johnston, and H. J. Snaith, Nature, 501 (2013) 395.

5. S.-Y. Hsiao, H.-L. Lin, W.-H. Lee, W.-L. Tsai, K.M. Chiang, W.-Y. Liao, C.-Z, Ren-Wu, C.-Y. Chen, and H.-W. Lin, Adv. Mater., 28 (2016) 7013.
6. H.-S. Kim, C.-R. Lee, J.-H. Im, L.-B. Lee, T. Moehl, A. Marchioro, S.-J. Moon, R. HumphryBaker, J.-H. Yum, J. E. Moser, M. Grätzel, and N.-G. Park, Sci. Rep., 2 (2012) 1.

7. L. Etgar, P. Gao, Z. Xue, Q. Peng, A. K. Chandiran, B. Liu, Md. K. Nazeeruddin, and M. Grätzel, J. Am. Chem. Soc., 134 (2012) 17396.

8. J.-H. Im,I.-H. Jang, N. Pellet, M. Grätzel, and N.G. Park, Nature Nanotechnol., 9 (2014) 927.

9. N. J. Jeon, J. H. Noh, W. S. Yang, Y. C. Kim, S. Ryu, J. Seo, and S. I. Seok, Nature Mater, 13 (2014) 897.

10. Z. Xiao, Q. Dong, C. Bi, Y. Shao, Y. Yuan, and J. Huang, Adv. Mater., 26 (2014) 65.

11. B. Lei, V. O. Eze, and T. Mori, Jpn J. Appl. Phys., 54 (2015) 100305.

12. V. O. Eze, B. Lei, and T. Mori, Jpn J. Appl. Phys., 55 (2016) 02BF08.

13. T. Mori, H. Okada, V. O. Eze, and Y. Seike, $J$. Photopolym. Sci. Technol., 33 (2020) 399.

14. V. O. Eze, Y. Seike, and T. Mori, ACS Appl. Mater. Interfaces, 12, 41 (2020) 46837.

15. B. Lei, V. O. Eze, and T. Mori, J. Nanosci. and Nanotechnol., 16 (2016) 3176.

16. V. O. Eze, Y. Seike, and T. Mori, Org. Electron., 46 (2017) 253.

17. X. Li, Y. Liu, V. O. Eze, T. Mori, Z. Huang, K. P. Homewood, Y. Gao, and B. Lei, Solar Ener. Mater. Solar Cells, 196 (2019) 157.

18. Y. Wu, A. Islam, X. Yang, C. Qin, J. Liu, K. Zhang, W. Peng, and L. Han, Energy \& Environ. Sci., 7 (2014) 2934.

19. W. Li, J. Fan, J. Li, Y. Mai, and L. Wang, J. Am. Chem. Soc, 137 (2015) 10399.

20. D.-H. Ma, W.-J. Zhang, Z.-Y. Jiang, D.-Y. Song, L. Zhang, and W. Yu, J. Phys. Chem. C, 121 (2017) 22607.

21. C.-Y. Long, N. Wang, K.-Q. Huang, H.-Y. Li, B. Liu, and J.-L. Yang, Chinese Phys. B, 29 (2020) 048801. 